\title{
TECTONOPHYSICS
}

Tectonophysics 307 (1999) 1-14

www.elsevier.com/locate/tecto

\section{Evolution of magnetic fabrics during incipient deformation of mudrocks (Pyrenees, northern Spain)}

\author{
Josep M. Parés a,*, Ben A. van der Pluijm ${ }^{\text {a }}$, Jaume Dinarès-Turell ${ }^{\mathrm{b}, 1}$ \\ ${ }^{a}$ Department of Geological Sciences, University of Michigan, 2534 C.C. Little Building, Ann Arbor, MI 48109-1063, USA \\ ${ }^{b}$ Institut de Ciències de la Terra, CSIC, Solé Sabarís s/n, 08028-Barcelona, Spain
}

Accepted 29 March 1999

\begin{abstract}
The anisotropy of magnetic susceptibility (AMS) of Eocene mudrocks from the Southern Pyrenean Foreland Basin documents the progressive development of tectonic fabrics in sediments that mesoscopically show no evidence for deformation. Two end members are observed: (1) a strong oblate fabric, with strong clustering of the minimum axes of susceptibility that is characteristic of depositional and compaction processes; and (2) a prolate magnetic ellipsoid with moderate to strong minimum axes girdle that reflects weak cleavage in the mudrocks. Low-temperature experiments and anhysteretic remanent magnetization reveal that the paramagnetic fraction dominates the AMS signal and thus, represent the preferred orientation of phyllosilicates. Characteristic stages of magnetic fabrics in mudrocks can be established and thus the AMS can be used as an indicator of cleavage development and intensity in mudrocks. The three stages of fabric development (early deformation, pencil structure and weak cleavage) reflect a process of increasingly preferred crystallographic orientation of the phyllosilicates that is evidenced by the change of distribution of the minimum susceptibility axes. This is particularly evident in the eigenvalues, which we plot on a Woodcock diagram that describes both shape and fabric strength, and allows different stages of deformation to be distinguished. Because appreciable depth during deformation (elevated temperatures and high confining pressures) can be ruled out, we propose that the sediments were wet and only partly lithified when the phyllosilicates became progressively reoriented. Thus, the observed fabric is explained as a result of the close interaction of deformation and diagenetic processes. Tectonically induced deformational fabrics formed while diagenesis progressed. Although the study area is a foreland basin, it offers a valuable analogue to active accretionary wedges. The application of AMS in these settings, where sediments are progressively dewatered through the development of fabrics, permits a similar quantification of fabric development and, eventually, of deformation. (C) 1999 Elsevier Science B.V. All rights reserved.
\end{abstract}

Keywords: cleavage; magnetic susceptibility; crystallographic preferred orientation; Pyrenean fold and thrust belt

\footnotetext{
*Corresponding author. Fax: +1-734-7634690; E-mail: jmpares@umich.edu

${ }^{1}$ Present address: Institut für Allg. und Angew. Geophysik, Ludwig-Maximilians Universität, Theresienstraße 41, 80333 München, Germany.
} 


\section{Introduction}

The anisotropy of magnetic susceptibility (AMS) has been shown to represent a measure of the crystallographic orientation of phyllosilicate and other tabular grains and, to a lesser extent, of the grain shape orientation of ferrimagnetic grains like magnetite. The magnetic anisotropy, a second-rank symmetric tensor, can be expressed in terms of three principal susceptibilities (maximum, intermediate and minimum susceptibility axes, or $K_{\max }, K_{\text {int }}$ and $K_{\min }$ hereafter). In non-deformed sedimentary rocks it has been observed that the AMS reflects the depositional surface. Thus, the magnetic foliation is parallel to the bedding plane and the magnetic lineation (if any) is parallel or normal to the paleocurrent direction, depending on the hydrodynamic regime. In moderately deformed rocks, the AMS is qualitatively related to the orientation of the strain ellipsoid; the $K_{\min }$ axis is normal to the cleavage and, thus, the magnetic foliation mimics the flattening plane. There are a wide variety of parameters that have been used to describe the axial magnitude relationships of the susceptibility ellipsoid. The simplest expressions are the axial ratios $L\left(K_{\max } / K_{\text {int }}\right), F\left(K_{\text {int }} / K_{\min }\right)$ and $P\left(K_{\max } / K_{\min }\right)$. Other authors though use the parameters $P^{\prime}\left(P^{\prime}=\right.$ $\left[\exp 2\left(a_{1}^{2}+a_{2}^{2}+a_{3}^{2}\right)\right]^{1 / 2}$ where $a_{1}=\ln \left(K_{\max } / K b\right)$, etc. and $\left.K b=\left(K_{\max }+K_{\text {int }}+K_{\min }\right) / 3\right)$ to express the fabric intensity as a measure of eccentricity and $T\left(T=2\left(\ln K_{\mathrm{int}}-\ln K_{\min }\right) /\left[\ln K_{\max }-\ln K_{\min }\right]-1\right)$ to define the degree to which the ellipsoid is oblate or prolate (Jelinek, 1981).

In recent years, a renewed interest in magnetic anisotropy research has occurred since Ising (1942) and Graham (1954) first proposed its application to geology. The method has been used to study a wide variety of problems ranging from such varied topics as the flow direction in igneous rocks, paleocurrents in deep-sea sediments to strain determination in deformed rocks. Moreover, magnetic fabric studies are an important complement to paleomagnetic studies, both as a means of determining magnetic mineralogy (since it studies the paramagnetic versus ferromagnetic contribution) and as a way to determine possible deformation-induced and compaction deflections in natural remanent magnetization (e.g., Fuller, 1963; Kligfield et al., 1983; Cogné et al., 1986; Hirt et al., 1986; Lowrie et al., 1986; Mothersill and Borradaile, 1989; Vetter et al., 1989; Jackson and Tauxe, 1991). Anisotropy of magnetic susceptibility has shown great potential first as a means of determining rock- and mineral-orientation fabrics (see reviews by Hrouda, 1982; MacDonald and Ellwood, 1987; Borradaile, 1988; Rochette et al., 1992; Borradaile and Henry, 1997), but also as a method of determining the kinematic history in deformed samples where conventional strain methods cannot be applied (e.g. Owens, 1974; Rathore, 1979; Hrouda, 1987).

In deformed rocks, the potential of susceptibility anisotropy as a strain gauge has received a lot of attention (e.g., Owens, 1974; Singh et al., 1975; Hrouda, 1976; Wood et al., 1976; Kligfield et al., 1977; Goldstein, 1980; Rathore et al., 1983; Henry and Daly, 1983; Borradaile, 1987; Cogné and Perroud, 1988; Hirt et al., 1988; Ruf et al., 1988; Pearce and Fueten, 1989; Kodama and Sun, 1990; Housen et al., 1995). The main reasons for this application are: (1) the relative ease by which the AMS ellipsoid can be established; (2) the sensitivity of the method to weakly developed rock fabrics; and (3) that essentially all rocks are magnetically anisotropic and therefore magnetic anisotropy offers a nearly universally applicable method to analyze deformation state of rocks, as opposed to the much smaller population of samples that may contain other strain indicators.

There is a growing body of literature on the variations of the magnetic susceptibility ellipsoid in deformed areas. Most of these studies propose models for the magnetic susceptibility ellipsoid based on the change of the scalar values of the principal axes. Nonetheless, none of them link the variations of the magnetic fabric to the initiation and development of incipient deformation fabrics in rocks; i.e., the existing studies do not correlate a specific AMS distribution or ellipsoid to a given petrofabric (pencil structure, cleavage intensity, etc.). However, most of the AMS studies concur that the AMS fabric is extremely sensitive and that it develops well before other mesoscopic strain features such as cleavage can be observed.

There is a general agreement in studies dealing with AMS development in weakly deformed rocks (e.g. Borradaile and Tarling, 1981, 1984; Kissel et al., 1986; Averbuch et al., 1992, 1995; Parés and Dinarès-Turell, 1993; Sagnotti and Speranza, 1993). 
The first effect from layer-parallel shortening is to group the $K_{\max }$ orientation normal to the shortening direction, producing a magnetic foliation parallel to the flattening plane. With further shortening, the $K_{\min }$ becomes distributed along a girdle that is parallel to the tectonic shortening direction, and the magnetic ellipsoid is prolate. Continued shortening returns the magnetic ellipsoid to the flattening field and the magnetic foliation becomes parallel to the flattening plane and mesoscopic cleavage. Housen and van der Pluijm (1991) and Averbuch et al. (1992) show examples of this sedimentary to tectonic fabric progression. An intermediate situation between sedimentary and tectonic fabrics is described by Kissel et al. (1986), Sagnotti and Speranza (1993), Parés and Dinarès-Turell (1993) and Aubourg et al. (1995), who report prolate magnetic fabrics (composite fabric) where the minimum axes describe a girdle parallel to the tectonic shortening direction.

Collectively, these studies show a lack of clear correlation between magnetic properties and the early stages of fabric development in mudrocks. In this study we present new AMS data from the Southern Pyrenean Foreland Basin that establish a relationship between magnetic fabric development and progressive deformation in mudrocks, from its earliest stage to well-developed cleavage.

\section{The South Pyrenean Foreland Basin: geological setting}

The Pyrenees formed during convergence between the Iberian and the European plates in latest Cretaceous to Oligocene times. The Ebro Basin, in the Southern Pyrenean Range, is located northeast of the Iberian Peninsula and developed as the Foreland Basin of the Pyrenees during Tertiary times (Fig. 1). The calculated shortening across the central Pyrenees is approximately $120 \mathrm{~km}$ (Deramond et al., 1985; Williams, 1985); however, in the eastern Pyrenees no calculation or total shortening has as yet been made. Balanced cross-sections across the southern side of the belt (Muñoz et al., 1986; Vergés and Martinez, 1988) show at least 50\% shortening, indicating that a total shortening of about $100 \mathrm{~km}$ is possible. In the foreland basin, well south of the belt, the subhorizontal Eocene rocks still exhibit a re- markable degree of deformation, of up to about $35 \%$ shortening (Casas et al., 1996). The main vergence of overthrusting was to the south, with subsidiary thrusting towards the north. As deformation progressed to the south, the foreland basin also migrated southwards, and was progressively incorporated into the younger thrust sheets. The sedimentology and stratigraphy of the Ebro Basin have been studied in detail in the region (see Anadón and Roca, 1997 and references therein). The base of the Tertiary beds in the Ebro Basin is very shallow in the southern part of the basin, and over $5000 \mathrm{~m}$ deep in the northern part. From the uppermost Cretaceous to the Late Eocene, the main trough of the southern foreland was connected to the Atlantic Ocean, giving rise to widespread marine deposition. A rapid Middle to Late Eocene transgression occurred leading to a thick marine sequence, during which the Igualada, Milany and Puigsacalm formations were deposited (Reguant, 1967; Ferrer, 1967; Gich, 1972) that include the mudrocks used in the present study.

\section{Sequence of fabric development in mudrocks}

Cleavage is commonly present in naturally deformed mudrocks. The orientation of the mineral fabric forms roughly perpendicular to the shortening axis ( $Z$-direction) of the finite strain ellipsoid, and increases in intensity with increasing strain (e.g. strain ratio $R x z$ ). The relationship between strain magnitude and cleavage intensity is qualitative, but can be examined quantitatively by magnetic fabric or by X-ray pole-figure analysis. Four main stages of fabric development can be distinguished in early cleavage formation (Ramsay and Huber, 1983):

\subsection{Undeformed condition}

Most undeformed shales contain a fabric as a result of sedimentation and diagenetic processes. Clay sedimentation commonly occurs as flocculated clay aggregates, internally characterized by a random orientation of the clay particles. These aggregates will eventually collapse, generating a clay particle preferred orientation arising from the stable hydrodynamic orientation of platy minerals parallel to paleohorizontal. The magnetic foliation also develops 


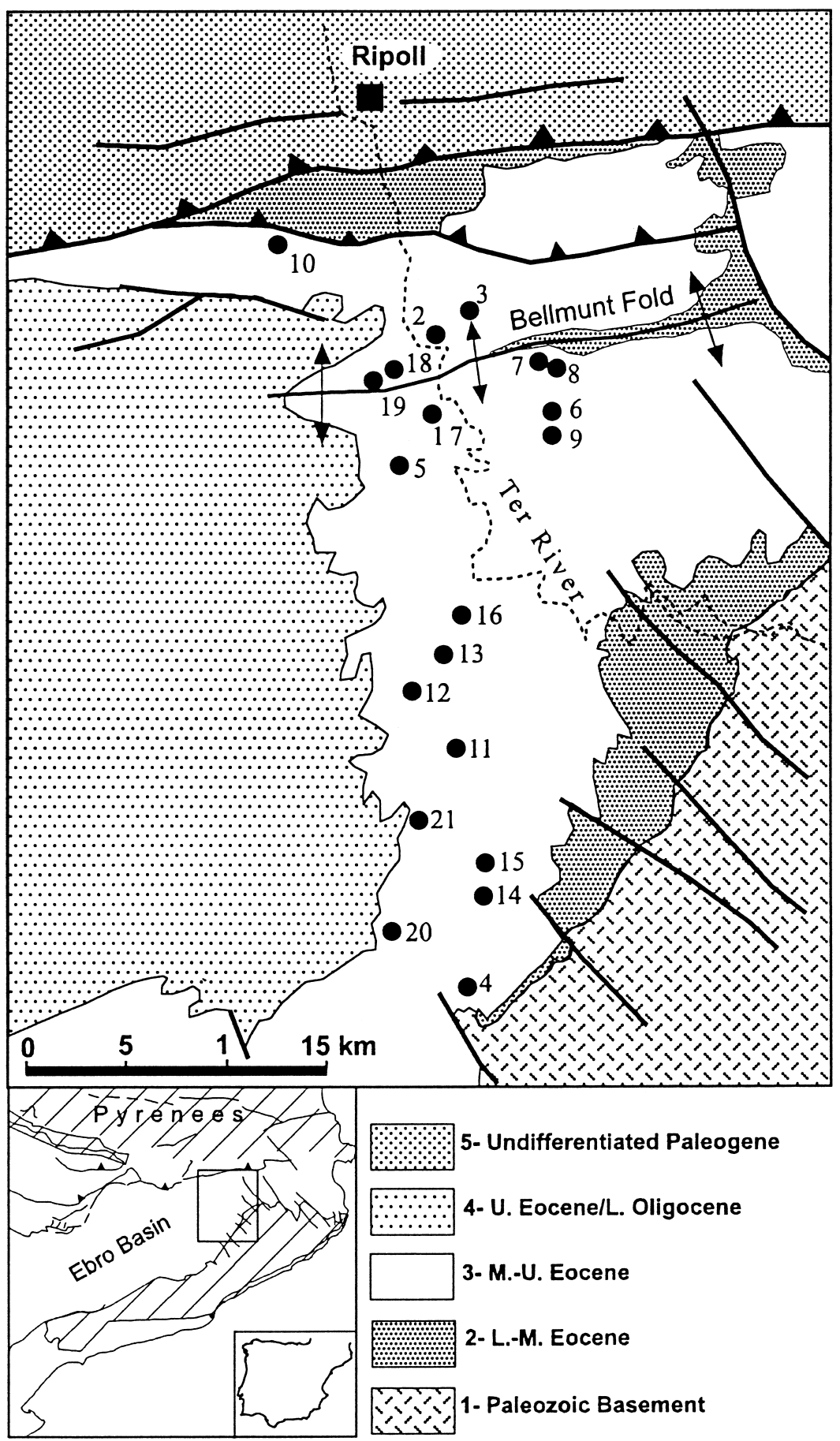

Fig. 1. Geological sketch map of the northeastern Pyrenean Foreland Basin, along the Ter-Freser Valley: $1=$ Paleozoic basement and Mesozoic cover of the Catalan Coastal Range; $2=$ red terrigenous rocks (Lower Eocene, Cuisian-Lutetian); $3=$ mudstones and fine-grained sandstones (including the Igualada Formation) (Middle-Upper Eocene, Bartonian-Priabonian); $4=$ mudstones and limestones (Upper Eocene-Lower Oligocene, Priabonian-Stampian); $5=$ undifferentiated Paleogene terrigenous rocks. 
from the effect of compaction on the clay minerals in the initial mud through overburden pressure and expulsion of pore water.

\subsection{Earliest deformation stage}

Early deformation is commonly accompanied by considerable volume loss as a result of mechanical closure of pore spaces left after diagenetic compaction and the expulsion of pore water contained in the initial shale. Elongation in the tectonic $X$-direction is small compared to the amount of shortening taking place (Ramsay and Huber, 1983). The initial planar fabric therefore is only slightly modified, with the bedding plane fabric less well defined through the mechanical rotation of platy elements around the tectonic $Y$-axis, and a very weak linear orientation of any elongate minerals that rotate towards the tectonic $Y$-direction.

\subsection{Pencil structure stage}

With increasing tectonic strain, perhaps accompanied by further volume loss, the finite strain ellipsoid (sedimentary + tectonic) takes on a more prolate form, eventually approaching a uniaxial prolate-shaped ellipsoid. The long axis of this ellipsoid is parallel to the tectonic $Y$-direction. At this stage the tectonic shortening is sufficient to compensate in the principal plane $X Z$ for the initial diagenetic fabric. This stage reflects the progressive rotation of clay flakes to a higher angle to the shortening direction. The mineral orientations are usually sufficient to produce a second mechanical weakness to the rock, producing the characteristic macroscopicscale pencil structure. This stage can be considered a 'snapshot' of an early stage in process by which slaty cleavage develops (Van der Pluijm and Marshak, 1997).

\subsection{Weak cleavage stage}

Increasing tectonic strain leads to reduction of the prolate nature of the finite strain ellipsoid and the progressive movement of the ellipsoid into the apparent flattening field of a Flinn plot diagram. These changes are caused by further shortening in the tectonic $Z$-direction and elongation in the $X$-direction.
At this stage mineral rotations lead to the production of a weak or incipient cleavage that crosscuts bedding, generally associated with a remnant pencil structure fabric parallel to the tectonic $Y$-direction. This stage corresponds to the 'embryonic cleavage stage' of Ramsay and Huber (1983).

\section{Magnetic susceptibility measurements}

\subsection{Source of the magnetic susceptibility}

The mineral dominating the susceptibility anisotropy determines the interpretation of AMS data, and therefore its identification is important. AMS residing in magnetite will reflect a preferred grain shape orientation, whereas AMS due to phyllosilicates or hematite will be related to their preferred crystallographic orientation (which may or may not reflect a grain shape orientation). Existing paleomagnetic results on the Igualada Formation indicate that magnetite, and iron sulfides to a much lesser extent, are the main ferromagnetic contributors to the Natural Remanent Magnetization (NRM; Parés et al., 1988; Dinarès-Turell, 1992; Burbank et al., 1992; Taberner et al., 1998). Anhysteretic Remanent Magnetization (ARM) and low-temperature susceptibility experiments on our samples corroborate these results (Fig. 2a). When increasing the alternating field window during the ARM experiment we observe a peak at about 200 Oe, suggesting the presence of magnetite of $\sim 5 \mu \mathrm{m}$ (Jackson et al., 1988). Despite the presence of magnetite, the bulk susceptibility of the mudrocks is quite low, in the order of $150 \times 10^{-6}$ SI, which argues against a significant contribution from magnetite to the susceptibility. We carried out low-temperature susceptibility measurements to determine the role of paramagnetic phases (Richter and van der Pluijm, 1994). Whereas diamagnetic susceptibility is independent of temperature, paramagnetic susceptibility $K_{\mathrm{p}}$ (largely due to phyllosilicates) increases with decreasing temperature $(T)$ according to $K_{\mathrm{p}}=C /(T-\phi)$, where $C$ is a constant and $\phi$ is the paramagnetic Curie temperature. Thus the temperature dependence of susceptibility can allow identification of paramagnetic components. Fig. $2 b$ shows low-temperature analysis of two representative mudstone samples. The prevalence of the para- 
a
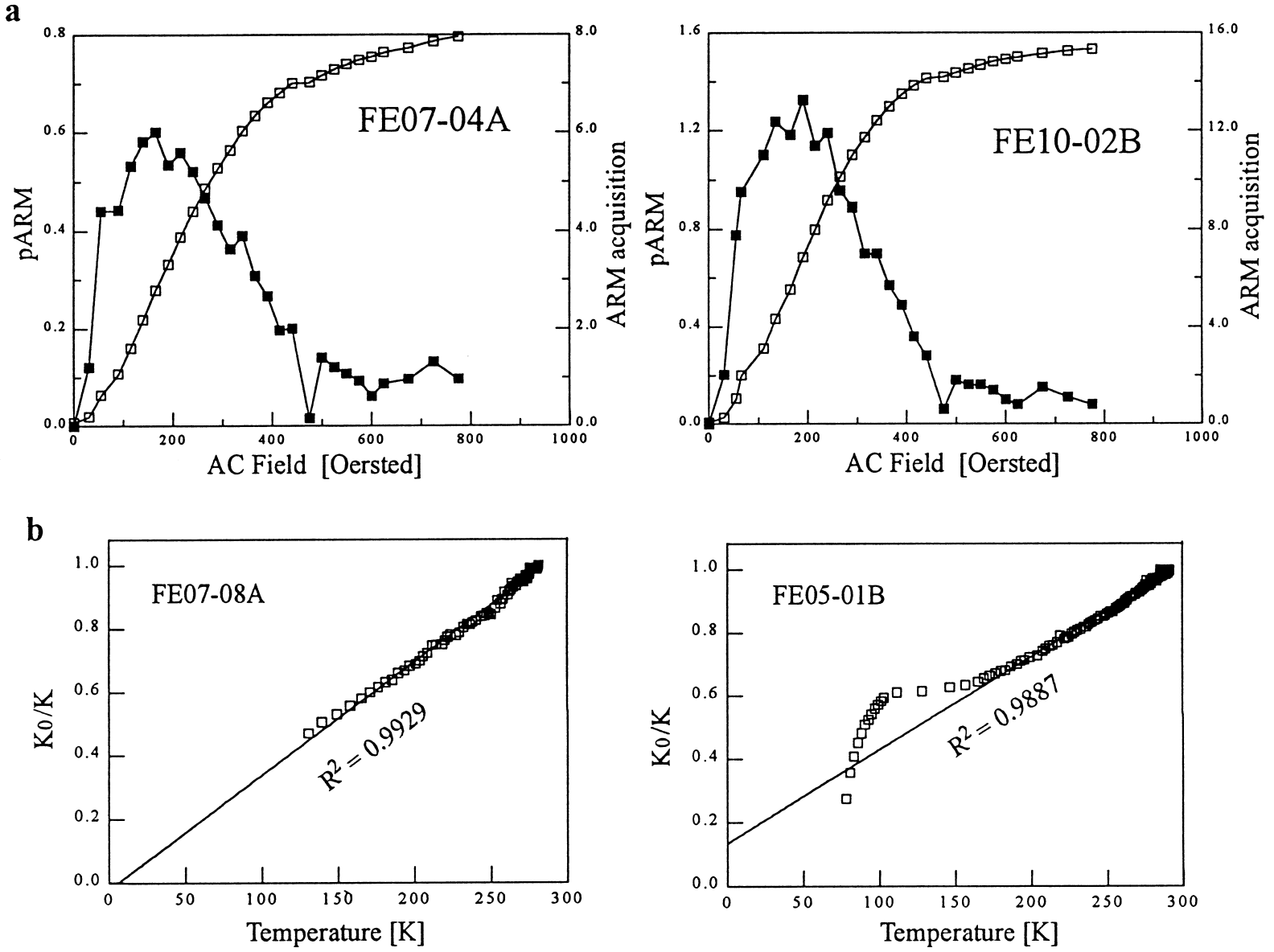

Fig. 2. (a) Acquisition of partial anhysteretic remanent magnetization for representative mudstone samples. The vertical axis is normalized magnetization, and the horizontal axis is the intensity of the AF used for the pARM step. Open symbols indicate the progressive acquisition of isothermal remanent magnetization (IRM), and closed symbols correspond to the acquisition of ARM. The peak at 170 Oe indicates a grain size of $5 \mu \mathrm{m}$ for the magnetite grains (Jackson et al., 1988). (b) Temperature dependence of low-field susceptibility for two mudstone samples, using the procedure of Richter and van der Pluijm (1994). $K_{0} / K$ is the normalized reciprocal magnetic susceptibility (reading temperature during warming up versus ambient temperature, $290 \mathrm{~K}$ ). Regression line on sample FE05-1B is calculated for $T$ greater than $150 \mathrm{~K}$ to exclude effects from the Verwey transition. The linear increase of the reciprocal susceptibility between $77 \mathrm{~K}$ and $290 \mathrm{~K}$ indicates that samples are dominated by paramagnetic mineral contributions. The $77 \mathrm{~K}$ measurements have an enhanced susceptibility and up to 3.4 times higher bulk susceptibility.

magnetic contribution leads to a linear increase of the susceptibility between 77 and $290 \mathrm{~K}$ and therefore the samples obey almost perfectly the CurieWeiss law. The ratio between susceptibility at $77 \mathrm{~K}$ and at room temperature is about 3.4 and thus the results indicate that the bulk susceptibility is dominated by paramagnetic minerals. In addition, sample FE05-01B show a susceptibility jump of around 120 $\mathrm{K}$ that coincides with a lattice transition in magnetite grains (Verwey transition). Thus, collectively the data show that paramagnetic minerals, here clay minerals, are the main contributors to the low-field susceptibility and thus the fabric can be interpreted in terms of preferred phyllosilicate grain orientation, though some local contribution of magnetite can not be ruled out (i.e. in pressure-solution planes, though not observed in the studied sites). X-ray diffraction data indicate that illite and chlorite are the main phyllosilicate minerals within these mudrocks (Parés and Dinarès-Turell, 1993). 


\subsection{Results of the AMS measurements}

The Ebro Basin is a typical foreland basin characterized by the development of folds and thrusts without metamorphism. The Bellmunt anticline is a concentric fold that represents the southernmost structure of the deformed foreland (Figs. 1 and 3). The Igualada Formation mudstones exhibit a spaced cleavage in a restricted area on both limbs of the Bellmunt fold, but we will present evidence that a tectonic fabric extends far southwards of the fold, within seemingly undeformed beds. Where observed, in the northern part of the basin, cleavage is perpendicular to bedding.

The variation of magnetic fabric as illustrated in a Woodcock diagram (Fig. 4, see explanation in Ap- pendix A) allows a subdivision into different stages of the deformation evolution shown in Fig. 5a. Results from site FE20, at the southern end of the study transect, show a significant dispersion of both $K_{\max }$ and $K_{\text {int }}$ (Fig. 3), resulting in an oblate magnetic ellipsoid (Fig. 5b). Similarly, site FE4 displays an oblate ellipsoid with minimum principal axes normal to bedding, reflecting the sedimentary origin of the AMS. Yet, the maximum principal axes $\left(K_{\max }\right)$ of these sites are subhorizontal and scattered around an E-W direction. This distribution of $K_{\max }$ is interpreted as a first effect of $\mathrm{N}-\mathrm{S}$ shortening in the Pyrenean Foreland Basin. Sites FE20, FE4, FE14 display a magnetic ellipsoid that is consistent with an original sedimentary fabric overprinted by some tectonic deformation. We consider these sites to rep-

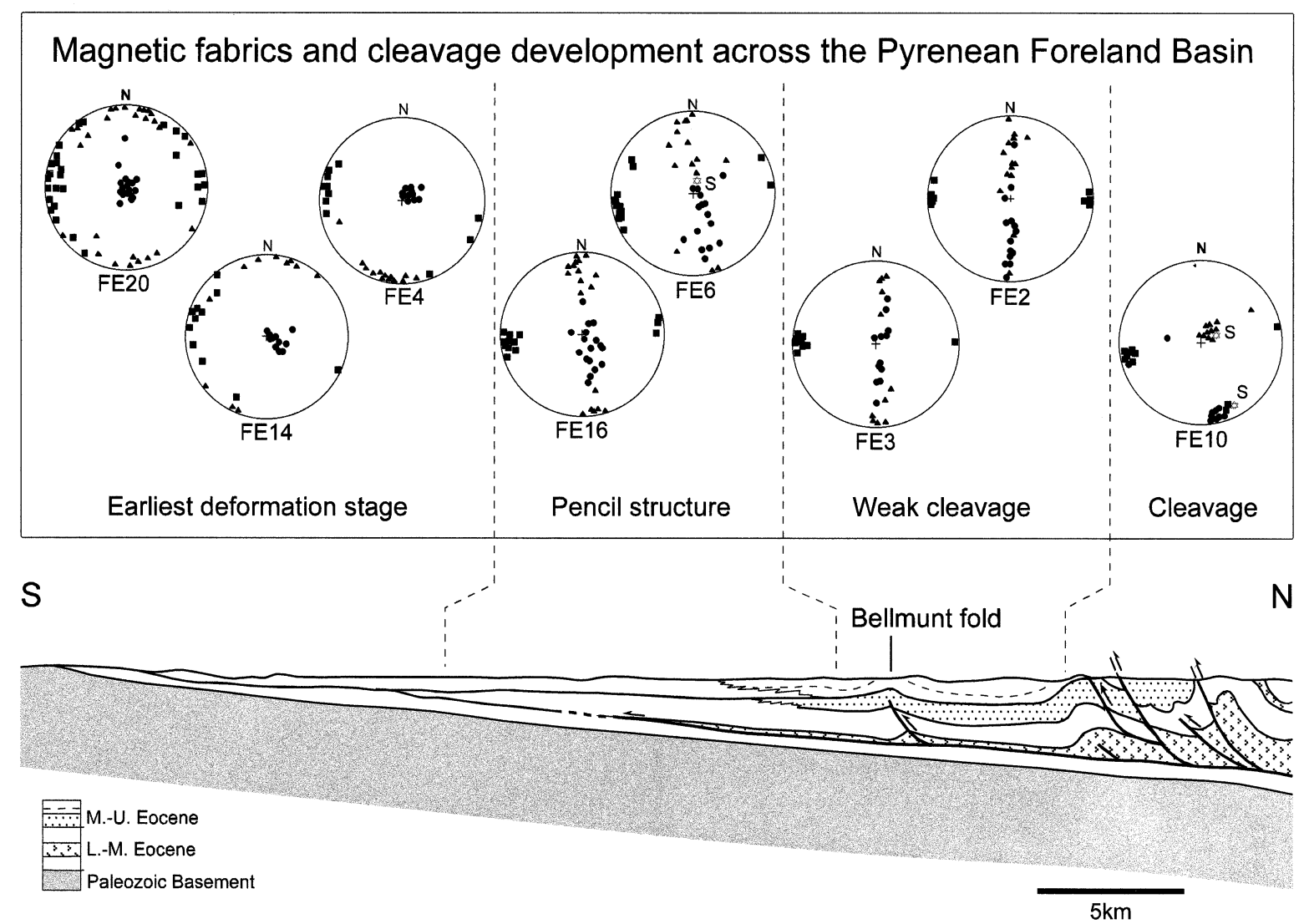

Fig. 3. Equal-area, lower-hemisphere projection of anisotropy of magnetic susceptibility data for representative sites along a $\mathrm{N}-\mathrm{S}$ section in the Ebro Basin, southern Pyrenees. Pole to bedding plane is only indicated when dip is larger than $5^{\circ}$. Note that most sites have their maximum axes parallel to the bedding-cleavage intersection. Minimum axes are grouped and normal to bedding/cleavage or they tend to scatter along a $\mathrm{N}-\mathrm{S}$ girdle. 


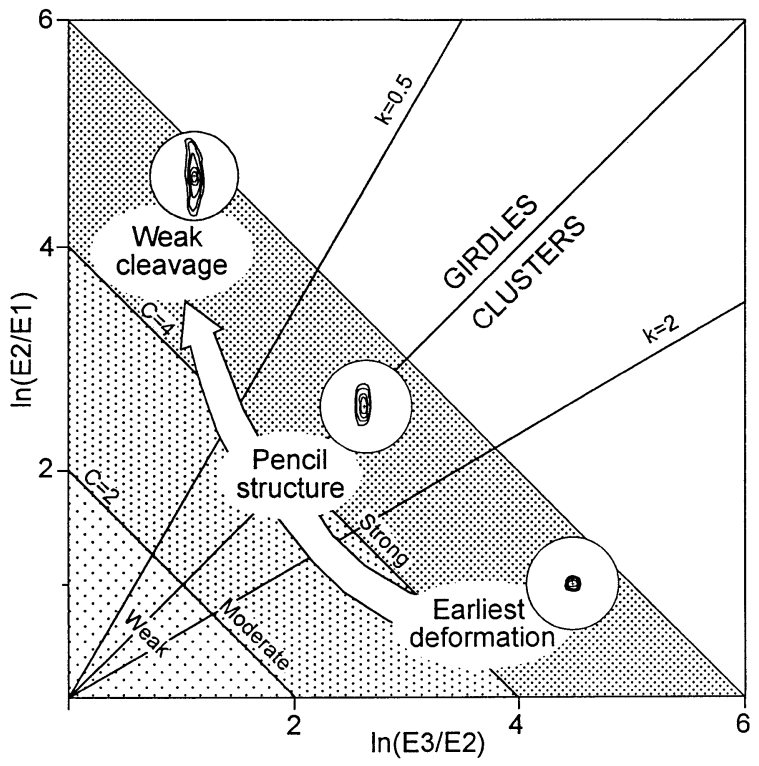

Fig. 4. Woodcock diagram showing the equivalence between AMS fabrics, represented as synthetic stereographic projections of $K_{\min }$ axes distribution, and stages of progressive deformation in mudrocks. The plot is two-axis logarithmic and uses ratios of the normalized eigenvalues E1, E2, E3 for the minimum axes of susceptibility. The parameter $K(\ln [E 1 / E 2] / \ln [E 2 / E 3])$ gives the shape of fabrics, whereas the parameter $c=\ln (E 3 / E 1)$ is a measure of the strength of the preferred orientation. Distributions that have equal girdle and cluster tendencies plot on the line where $K=1$. Girdles plot above this line in the field where $0<K<1$, and clusters plot below where $1<K<\infty$. Contour lines in the stereographic projection represent the distribution of minimum susceptibility axes (see Appendix A for detailed discussion of diagram).

resent the earliest deformation stage (Section 3), characterized by a slight rotation of platy elements around the E-W direction, i.e., the fold axis direction in the basin. As in the 'undeformed stage', the minimum axes of susceptibility have a strong vertical cluster, but unlike the 'undeformed stage', the maximum axes cluster around the $\mathrm{E}-\mathrm{W}$ direction. These sites thus, reveal that the tectonic component is sufficiently developed to combine with the persistent sedimentary oblate ellipsoid to yield $K_{\max }$ parallel to the intersection of 'nascent' cleavage and bedding. Notice that in such situation, $K_{\max }$ does not represent the $X$-strain axis, but the $Y$-axis.

Toward the north the magnetic fabric displays moderate changes (Fig. 3). In sites FE6 and FE16, where bedding is flat, $K_{\min }$ axes range from verti-
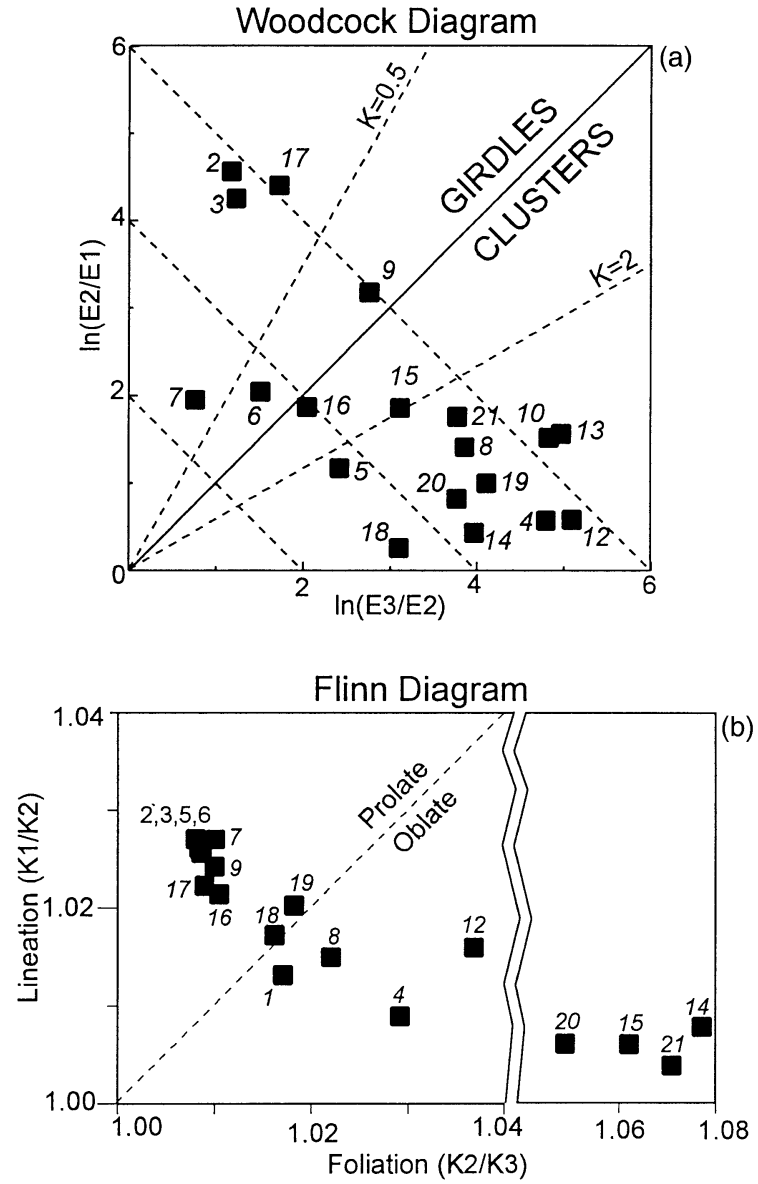

Fig. 5. Comparison between Woodcock diagram (a) and Flinn diagram (b) for the studied sites. Data points (black squares) correspond to the sites shown in Fig. 1. Symbols as in Fig. 4. The Woodcock diagram is based on the eigenvalues of $K_{\min }$ axes and reflects their distribution (girdle or cluster) and strength of the preferred orientation (weak, moderate or strong).

cal to southerly plunging, and form pseudo-girdles of $<60^{\circ}$. The corresponding magnetic ellipsoid is strongly prolate (Fig. 5b). The minimum axes distributions on the Woodcock diagram for fabric shape and strength form a strong to moderate cluster and girdle (Figs. 4 and 5a). This AMS pattern relates to the 'pencil structure stage', with the longest axis parallel to the tectonic $Y$-direction.

The 'weak cleavage stage' is represented by a girdle distribution of the minimum axes (Fig. 4), whereas the magnetic ellipsoid is prolate (Fig. 5b). Sites FE2 and FE3, on the north side of the Bell- 
munt fold, are good examples of this deformation stage, that is evidenced by a semi-girdle distribution of $K_{\min }$, from horizontal to very steep inclinations. The magnetic susceptibility ellipsoids for these sites reflect an intermediate position between the sedimentary-oblate ellipsoids and the tectonicoblate ellipsoids, as predicted in numerical models and observed in other deformed regions (Housen et al., 1993; Aubourg et al., 1995; Borradaile and Henry, 1997). This composite fabric reflects the amount of bedding-parallel phyllosilicates relative to the amount of grains that are rotated into the plane of tectonic flattening or into some intermediate position between both bedding and flattening planes.

\section{Discussion and conclusions}

Our results indicate that the magnetic fabric is a sensitive indicator of progressive deformation in weakly deformed mudrocks (Figs. 4 and 6). We observe characteristic geometries as a function of degree of cleavage development. The earliest deformation is characterized by grouping of the maximum susceptibility axis and preservation of the minimum axis normal to bedding. The minimum axes show then a moderate/strong cluster on the Woodcock diagram $(K>2)$ (Fig. 4). The pencil structure stage, is characterized by prolate magnetic ellipsoids in the Flinn diagram, where the maximum axes are grouped parallel to the E-W direction and the minimum axes are distributed along a moderate girdle with $0.5<K<2$ on the Woodcock diagram (Fig. 4). This fabric represents a combination of sedimentary and tectonic contributions, and the maximum susceptibility is parallel to the intersection lineation of the flattening plane and bedding. The explanation that we favor is that the maximum susceptibility axis is the intersection axis between phyllosilicate crystals. As they rotate around an axis parallel to the folding axis, the phyllosilicate plates 'intersect' parallel to that direction and that gives the direction of maximum susceptibility. Bouchez (1997) envisages a similar mechanism to explain the AMS in granites. The lineation marked by the biotite grains in granites is, according to that author, a zone axis, or the statistically defined axis of rotation of the population of crystals. The weak cleavage

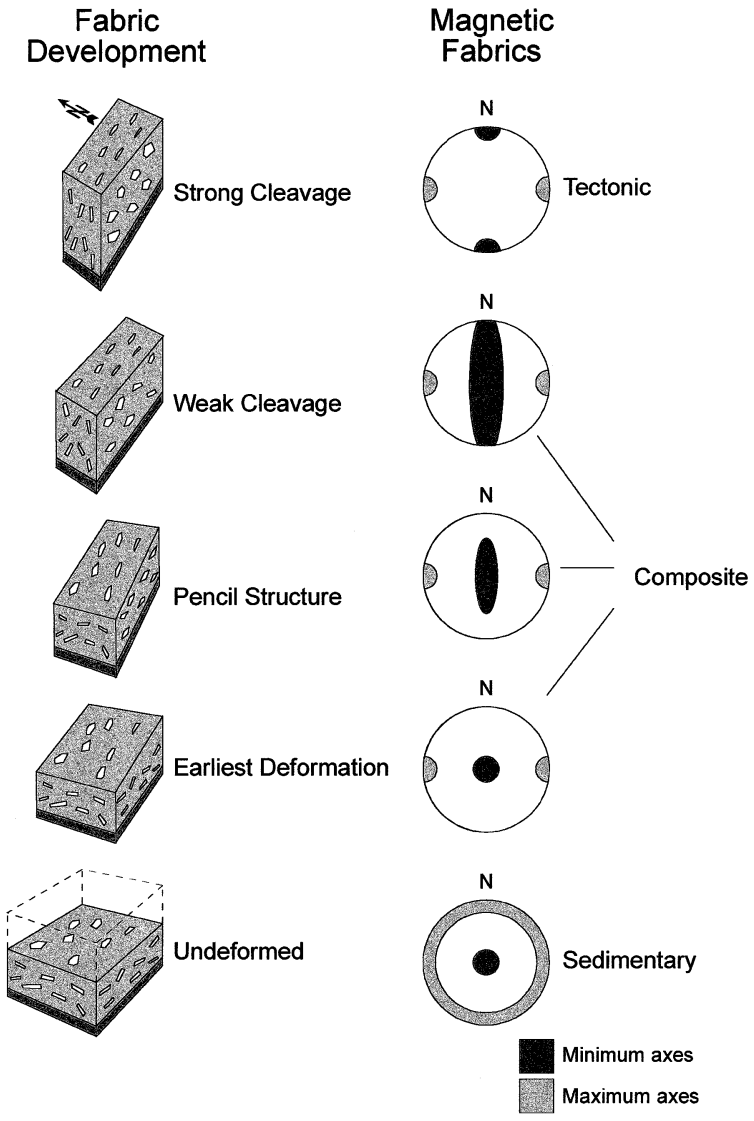

Fig. 6. Sequence of fabric development in progressively cleaved mudrocks and associated magnetic fabrics. The rock texture is after Ramsay and Huber (1983), but we slightly modified the terminology. The magnetic fabrics are characterized by the distributions of the maximum and minimum susceptibility axes.

stage is characterized by moderate/strong girdles of minimum axes $(K<0.5)$, whereas the magnetic ellipsoid is still prolate. Cleavage might be visible in outcrop at this stage. As the cleavage becomes stronger, the distribution of minimum axes changes into a cluster that is normal to the cleavage plane. In Fig. 6 we schematically show the relationship between the different stages of fabric development and the corresponding magnetic fabrics expressed by the $K_{\max }$ and $K_{\min }$ axes distributions.

\subsection{A mechanism for grain-reorientation}

The data shown here indicate that phyllosilicates (chlorite and illite) are the main sources of the AMS, 
and that the orientations of the principal axes of susceptibility are produced by the spatial organization of the basal planes of these platy minerals. In a study of the Lehigh Gap mudstone-to-slate transition, Housen and van der Pluijm (1991) noticed that dissolution and new growth of paramagnetic minerals such as chlorite results in AMS fabrics that do not reflect the dominant rock fabric in these samples. In general, if the grain growth takes place prior to deformation, then these minerals will be reliable markers of the finite strain. In contrast, if the new grains grow during or after deformation then they do not reflect the total deformation of the sediment, but only part of it or none. This is important for the interpretation of the results, as will be discussed in Appendix A. Phyllosilicate minerals have their minimum susceptibility axis sub-parallel to the crystallographic $c$-axis, whereas the intermediate and maximum axes lie in their basal plane. Thus, the orientations of the AMS axes are a reflection of the preferred crystallographic orientation of phyllosilicate crystals within the sediment. The distribution of the susceptibility axes, as shown in Fig. 3, can be explained in terms of progressive phyllosilicate grain reorientation. Two contrasting mechanisms produce grain reorientation in mudrocks: (a) crystal plastic deformation of grains and grain growth, and (b) physical rotation. The pressure-temperature conditions within the Pyrenean Foreland Basin are well below greenschist metamorphic facies, so crystal plasticity is an unlikely mechanism. Moreover, thin section analysis does not reveal significant new growth in the mudstones, nor pressure-solution. Geological evidence shows that the maximum depth of the studied Eocene mudrocks was less than $1000 \mathrm{~m}$ (Gimènez-Montsant and Salas, 1997; Taberner et al., 1998 ) and thus the $P-T$ conditions are limited to diagenesis. At this depth, the sediments could have been only partially lithified when the deformation took place during the Eocene. Either a fluid or a sediment-fluid mixture between grains is required to effect particulate flow (Borradaile, 1981). At such conditions, grain-boundary sliding and grain rotation will be the mechanism that dominates fabric evolution. The existence of a fluid within the pores of the rock reduces normal stress, i.e., fluid pressure reduces normal stresses between grains. Since the sliding friction on particle contacts is directly proportional to the normal stress acting across the contact, particulate flow will be easier where the normal stresses are reduced by fluid pressure. Thus, physical rotation of phyllosilicate grains under layerparallel shortening appears to be the most suitable mechanism to explain the AMS fabrics of the studied mudrocks. Fluid flow due to prelithification tectonic dewatering could alternatively produce a grain preferred orientation by realigning particles parallel to fold axial planes, a mechanism suggested by Paterson and Tobisch (1993) that cannot be completely ruled out.

The underlying mechanical model is a rigid-body rotation, in which platy elements that may or may not impinge on one another, become systematically reoriented under homogeneous strain. Several authors have simulated the distributions of platy grains to explain and model AMS observations (e.g. Richter et al., 1993; Benn, 1994) and results show that even small strains modify a pre-existing AMS fabric. Phyllosilicate grains generally seem to resist comminution, so if each large face of a single grain is in contact with several neighboring grains, then the phyllosilicates behave similar to grains suspended in a fluid (Oertel, 1983). Preferred crystallographic orientation can therefore be explained in terms of intergranular slip combined with rigid-body rotation of grains. The question whether the fabric of rotated grains is characterized by pervasive phyllosilicate alignment or by reorientation in discrete zones (domainal mineral alignment or 'stripes', Durney and Kisch, 1994) can not be answered by the scale of our measurements. Given (1) the absence of metamorphism during deformation in the Ebro Basin, and (2) the feasibility of grain sliding and rotation as the mechanism responsible for phyllosilicate reorientation, we suggest that the preferred crystallographic orientation in these mudrocks formed when the sediment was only partially lithified and thus relatively soft. These deformation conditions are similar to those observed in accretionary wedges at convergent margins, where sediments are progressively dewatered and deformed by the development of tectonic fabrics at various scales (Moore, 1986). Thus, AMS studies could conceivably be able to characterize deformation stages in accretionary wedges, where other methods show little or no strain accumulation. 


\section{Acknowledgements}

Research was partially supported by the National Science Foundation, grant EAR-9814343, and by the DGES, grant PB96-0815. We thank Editor K. Benn and the reviewers O. Averbuch and J. Hodych for their comments that led to improvement of the manuscript. We also thank J.M. Casas, D. Durney and J.A. Muñoz for discussions at different stages of this work.

\section{Appendix A. Modified Flinn diagram for magnetic data}

Graphic representation of the magnetic ellipsoid has typically relied on the 'Flinn-type' diagram (Flinn, 1962). In these diagrams, the magnetic lineation $(K 1 / K 2)$ is plotted against the magnetic foliation $(K 2 / K 3)$, allowing for a distinction between oblate and prolate magnetic ellipsoids. Another type of AMS graphic representation, preferred by several workers, is the $P^{\prime}-T$ plot that was initially introduced by Hrouda (1982) using expressions from Jelinek (1981). The advantage of the later plot is that ellipticity of the fabric is better defined: the eccentricity of the ellipsoid is plotted as $P^{\prime}$ on the horizontal axis $\left(1<P^{\prime}<\infty\right)$ and the symmetry of shape as $T$ on the vertical axis $(-1<T<1)$. In progressive deformation, these plots are partially successful in showing the path of the magnetic ellipsoids. The shape of the magnetic fabric ellipsoids displays a characteristic progression from oblate (sedimentary) to prolate and back to oblate field (tectonic). This ellipsoid evolution has been observed in experiments as well as in naturally deformed rocks.

In several magnetic fabric studies, it has been shown that the change of the ellipsoids from oblate to prolate is very rapid, and that there is almost no transition between this two situations, as the maximum axes are highly sensitive to very low degrees of deformation. In addition, during further deformation, the maximum susceptibility axes remain stationary. As a consequence, most of the magnetic ellipsoid evolution path takes place within the same region on the prolate field and therefore both Flinn and Jelinek plots fail to recognize potentially different histories.

Maximum axes oriented at the bedding-flattening plane intersection have been shown in many magnetic anisotropy studies (see Borradaile, 1988 for review). In laboratory experiments it has also been observed that maximum axes are always oriented at the intersection of two planar fabrics. Yet, changes in the shape and degree of anisotropy of susceptibility due to either (a) the change of angle between planar fabrics or (b) the relative intensity of the component fabrics, are not reflected in the maximum axes distribution. Rather in the minimum axes distribution, because the former generally remain at the intersection of the two planar fabrics. Upon progressive mineral re-orientation, the magnetic anisotropy degree increases with increasing crystallographic preferred orientation, and it reaches a saturation value that is defined by the single mineral anisotropy. For aggregates of perfectly oblate particles the saturation anisotropy is reached twice as fast for the maximum axes than for the minimum axes (Borradaile, 1988). Thus the minimum axis is a better indicator of the degree of crystallographic preferred orientation (Richter et al., 1993). Based on this conclusion, we use the orientation of minimum susceptibility axes to compute three eigenvectors $\left(v_{1}\right.$, $\left.v_{2}, v_{3}\right)$ and the corresponding eigenvalues $\left(l_{1}, l_{2}, l_{3}\right)$ and plot these on a two-axis plot (Woodcock, 1977). If observations are regarded as points of unit mass on the sphere, then eigenvector $v_{1}$ may be considered as the direction about which the 'moment of inertia' of the distribution is minimized (Watson, 1966). This eigenvector is an estimate of the distribution mean. Conversely, eigenvector $v_{3}$ is associated with the largest moment of inertia. It is an estimate of the pole to the best-fit girdle to the distribution, provided that the data do not form an axially symmetric cluster. The eigenvalues $l_{1}, l_{2}, l_{3}$ are more useful in a normalized form (so that $E 1+E 2+E 3=1$ ) and are a measure of the degree of clustering about the respective eigenvectors. Watson (1966) noted that clusters would tend to have $E 3>E 2 \sim E 1$, and great circles $E 3 \sim E 2>E 1$. Thus the eigenvalues directly relate to fabric shape.

We have used the two-axis ratio of Woodcock (1977) to plot the magnetic fabric shape and strength. This plot is based on a procedure that determines the eigenvectors and eigenvalues of an orientation tensor derived from directional data. Two ratios of the three eigenvalues are plotted on a natural logarithmic scale. In this type of graph, uniaxial clusters plot where $E 2=E 1$, i.e., along the line $\ln (E 2 / E 1)=0$. Axially symmetric great-circle girdles plot where $E 3=E 2$, i.e. along the line $\ln (E 3 / E 2)=0$. The remainder of the graphs is occupied by distributions that have both girdle and cluster components. These can be quantified by a parameter $K$ :

$K=\ln (E 3 / E 2) / \ln (E 2 / E 1)$

This parameter gives the gradient of straight lines radiating from the origin. So distributions that have equal girdle and clusters components plot on the line where $K=1$, i.e. where $E 3 / E 2=E 2 / E 1$. Girdles plot above this line, in the field where $0<K<1$ and clusters plot below this line, where $1<K<\infty$. Uniform distributions plot at the origin, random distributions near the origin, and those with increasingly stronger preferred orientation lie progressively farther from the origin. The parameter $c$ is a measure of the strength of the preferred orientation (weak, moderate, strong, see Fig. 4):

$c=\ln (E 3 / E 1)$

The advantage of using this plot is that it allows to define and characterize the magnetic fabrics on the basis of the minimum axes distribution that would be indistinguishable in the Flinn or Hrouda-Jelinek plots (Fig. 5). The Woodcock-type diagram is particularly useful for the recognition of anisotropy susceptibility fabric paths within the prolate field, and where there are little changes in the anisotropy degree. In the case of the example shown (Fig. 5), the advantage in using the eigenvalues diagram is apparent. The sites showing less deformation (site FE20) have their minimum axes vertical and normal to the bedding plane. The magnetic ellipsoids lie in the flattening field of the Flinn 
diagram, with $L=K 1 / K 2$ very low. On the fabric shape diagram, these sites reveal a 'strongly developed cluster' of the minimum axes. Sites that display composite fabrics have girdles of minimum and intermediate axes, revealing the competition between bedding and cleavage fabrics. Prolate magnetic ellipsoids characterize the composite fabrics (e.g. sites FE2, FE3, FE9, FE17). The composite fabric reveals the changing proportion of the amount of bedding-parallel phyllosilicates and the amount of grains that are rotated into the plane of flattening tectonic or in some intermediate position. In these sites, both magnetic lineation and foliation have very similar values, as shown on a Flinn diagram. On the other hand, the 'girdle tendency' of these sites can be quantified by the $K$ parameter on the Woodcock diagram $(\ln [E 3 / E 2] / \ln [E 2 / E 1])$, and allows distinctions among these prolate ellipsoids. We observe two subgroups: those with 'moderately developed girdle' representing least deformed rocks, and those with 'strongly developed girdle' representing more deformed rocks. Note that in this graph, girdles plot above the line where $E 3 / E 2=E 2 / E 1$, i.e. $K=1$, whereas clusters plot below that line, where $1<K<\infty$. In contrast, in the Flinn diagram these sites all fall in the same region of the prolate field, preventing any distinction between them. For more deformed rocks (e.g. sites FE8, FE10), with cleavage fabric dominant over bedding fabric, the magnetic ellipsoid is oblate and thus similar to the bedding fabric, where all three axes show clusters. On the Woodcock diagram both bedding and cleavage fabrics give 'strong clusters', hampering the distinction between them in terms of minimum axes distribution. Nonetheless, at this deformation stage, cleavage is apparent in the field. On the Flinn diagram, the bedding fabric is characterized by a very high magnetic foliation, given that both intermediate and maximum axes tend to scatter along the bedding plane.

Thus, the Woodcock diagram is particularly useful when dealing with scattering of susceptibility axes within a plane, as it evaluates distributions. In weakly deformed rocks, where both bedding and tectonic fabrics compete, the eigenvalues of the scattered axes are a sensitive way to classify and quantify the fabrics and to establish the fabric path.

\section{References}

Anadón, P., Roca, E., 1997. Geological setting of the Tertiary basins of Northeast Spain. In: Friend, P.F., Dabrio, C.J. (Eds.), Tertiary Basins of Spain. Cambridge University Press, Cambridge, pp. 43-48.

Aubourg, C., Rochette, P., Bergmüller, F., 1995. Composite magnetic fabric in weakly deformed black shales. Phys. Earth Planet. Inter. 87, 267-278.

Averbuch, O., Frizon de Lamotte, D., Kissel, C., 1992. Magnetic fabric as a structural indicator of the deformation path within a fold-thrust structure: a test case from the Corbieres (NE Pyrenees, France). J. Struct. Geol. 14, 461-474.

Averbuch, O., Mattei, M., Kissel, C., Frizon de Lamotte, D., Speranza, F., 1995. Cinématique des déformations au sein d'un système chevauchant aveugle: l'exemple de la Montagna dei Fiori (front des Apennins centraux, Italie). Bull. Soc. Géol. Fr. 166, 451-461.

Benn, K., 1994. Overprinting of magnetic fabrics in granites by small strains: numerical modelling. Tectonophysics 1994 , 153-162.

Borradaile, J.G., 1981. Particulate flow of rock and the formation of cleavage. Tectonophysics 72, 305-321.

Borradaile, G., 1987. Anisotropy of magnetic susceptibility: rock composition versus strain. Tectonophysics 138, 327-329.

Borradaile, G.J., 1988. Magnetic susceptibility, petrofabrics and strain. Tectonophysics 156, 1-20.

Borradaile, G.J., Henry, B., 1997. Tectonic applications of magnetic susceptibility and its anisotropy. Earth Sci. Rev. 42, 4993.

Borradaile, G.J., Tarling, D., 1981. The influence of deformation mechanisms on magnetic fabrics in weakly deformed rocks. Tectonophysics 77, 151-168.

Borradaile, G.J., Tarling, D., 1984. Strain partitioning and magnetic fabrics in particulate flow. Can. J. Earth Sci. 21, 694697.

Bouchez, J.L., 1997. Granite is never isotropic: an introduction to AMS studies of granitic rocks. In: Bouchez, J.L. et al. (Eds.), Granite: From Segregation of Melt to Emplacement Fabrics. Kluwer, Rotterdam, pp. 95-112.

Burbank, D.W., Puigdefabregas, C., Muñoz, J.A., 1992. The chronology of the Eocene tectonic and stratigraphic development of the eastern Pyrenean foreland basin, northeast Spain. Geol. Soc. Am. Bull. 104, 1101-1120.

Casas, J.M., Durney, D., Ferret, J., Muñoz, J.A., 1996. Determinacion de la deformacion finita en la vertiente sur del Pirineo oriental a lo largo de la transversal del rio Ter. Geogaceta 20, 803-805.

Cogné, J.P., Perroud, H., 1988. Anisotropy of magnetic susceptibility as a strain gauge in the Flamanville granite, NW France. Phys. Earth Planet. Inter. 51, 264-270.

Cogné, J.P., Perroud, H., Texier, M.P., Bonhommet, N., 1986. Strain reorientation of hematite reorientation of hematite and its bearing upon remanent magnetization. Tectonics 5, 753767.

Deramond, J., Graham, R.H., Hossak, J.R., Baby, P., Crouzet, G., 1985. Nouveau modèle de la chaine des Pyrénées. C.R. Acad. Sci. Paris 301, 1213-1216.

Dinarès-Turell, J., 1992. Paleomagnetisme a les unitats sudpirenenques superiors. Implicaciones estructurals. $\mathrm{PhD}$ Thesis, Universitat de Barcelona, $451 \mathrm{pp}$.

Durney, D.W., Kisch, H., 1994. A field classification and intensity scale for first-generation cleavages. J. Aust. Geol., Geophys. 15, 257-295.

Ferrer, J., 1967. Le Paleogéne et l'Eocène des Cordillères cotieres de la Catalogne (Espagne). Eclogae Geol. Helv. 60, $567-575$.

Flinn, D., 1962. On folding during three-dimensional progressive deformation. Geol. Soc. London Q. J. 118, 385-433.

Fuller, M.D., 1963. Magnetic anisotropy and paleomagnetism. J. Geophys. Res. 68, 293-309.

Gich, M., 1972. Estudio geológico del Eoceno prepirenaico del 
Ripollés Oriental. PhD Thesis, Universitat de Barcelona, 477 pp.

Gimènez-Montsant, J., Salas, R., 1997. Subsidence analysis in thrust tectonics. Application to the Southeastern Pyrenees. Tectonophysics 282, 331-352.

Goldstein, A.G., 1980. Magnetic susceptibility anisotropy of mylonites from the Lake Char mylonite zone, southeastern New England. Tectonophysics 66, 197-211.

Graham, J.W., 1954. Magnetic susceptibility anisotropy, an unexploited petrofabric element. Geol. Soc. Am. Bull. 65, 12571258.

Henry, B., Daly, L., 1983. From qualitative to quantitative magnetic anisotropy analysis: the prospect of finite strain calibration. Tectonophysics 98, 327-336.

Hirt, A.M., Lowrie, W., Pfiffner, O.A., 1986. A paleomagnetic study of tectonically deformed red beds of the lower glarus nappe complex, eastern Switzerland. Tectonics 5, 723-731.

Hirt, A.M., Lowrie, W., Clendenen, W.S., Kligfield, R., 1988. The correlation of magnetic anisotropy with strain in the Chelmsford Formation of the Sudbury Basin, Ontario. Tectonophysics 145, 177-189.

Housen, B.A., van der Pluijm, B.A., 1991. Slaty cleavage development and magnetic anisotropy fabrics. J. Geophys. Res. 96, 9937-9946.

Housen, B., Richter, C., van der Pluijm, B.A., 1993. Composite magnetic anisotropy fabrics: experiments, numerical models, and implications for the quantification of rocks fabrics. Tectonophysics 220, 1-12.

Housen, B., van der Pluijm, B.A., Essene, E.J., 1995. Plastic behavior of magnetite and high strains obtained from magnetic fabrics in the Parry Sound shear zone, Ontario Grenville Province. J. Struct. Geol. 17, 265-278.

Hrouda, F., 1976. The origin of cleavage in the light of magnetic anisotropy investigations. Phys. Earth Planet. Inter. 13, 132142.

Hrouda, F., 1982. Magnetic anisotropy of rocks and its application in geology and geophysics. Geophys. Surv. 5, 37-82.

Hrouda, F., 1987. Mathematical model relationship between the paramagnetic anisotropy and strain in slates. Tectonophysics $142,323-327$.

Ising, G., 1942. On the magnetic properties of varved clay. Ark. Mat. Astron. Fys. 29a, 1-37.

Jackson, M., Tauxe, L., 1991. Anisotropy of magnetic susceptibility and remanence: development in the characterization of tectonic, sedimentary and igneous fabric. Rev. Geophys. Suppl., pp. 371-376.

Jackson, M., Gruber, W., Marvin, J., Banerjee, K., 1988. Partial anhysteretic remanence and its anisotropy: applications and grainsize-dependence. Geophys. Res. Lett. 15, 440-443.

Jelinek, V., 1981. Characterization of the magnetic fabric of rocks. Tectonophysics 79, 63-67.

Kissel, C., Barrier, E., Laj, C., Lee, T.Q., 1986. Magnetic fabric in 'underformed' marine clays from compressional zones. Tectonics 5, 769-781.

Kligfield, R., Lowrie, W., Dalziel, I.W.D., 1977. Magnetic susceptibility anisotropy as a strain indicator in the Sudbury basin, Ontario. Tectonophysics 40, 287-308.
Kligfield, R., Lowrie, W., Hirt, A., Siddans, A.W.B., 1983. Effect of progressive deformation on remanent magnetization of Permian redbeds from the Alpes Maritimes (France). Tectonophysics 97, 59-85.

Kodama, K.P., Sun, W.W., 1990. SEM and magnetic fabric study of a compacting sediment. Geophys. Res. Lett. 17, 795-798.

Lowrie, W., Hirt, A.M., Kligfield, R., 1986. Effects of tectonic deformation on the remanent magnetization of rocks. Tectonics 5, 713-722.

MacDonald, W.D., Ellwood, B.B., 1987. Anisotropy of magnetic susceptibility: sedimentological, igneous, and structural-tectonic applications. Rev. Geophys. 25, 905-909.

Moore, J.C., 1986. Structural fabrics in deep sea drilling project cores from forearcs. Geol. Soc. Am. Mem. 166, 160 pp.

Mothersill, J., Borradaile, G., 1989. Tectonic strain and paleomagnetism: experimental investigation. Phys. Earth Planet. Inter. 56, 254-265.

Muñoz, J.A., Martinez, A., Vergés, J., 1986. Thrust sequence in the eastern Pyrenees. J. Struct. Geol. 8, 399-405.

Oertel, G., 1983. The relationship of strain and preferred orientation of phyllosilicate grains in rocks - a review. Tectonophysics 100, 413-447.

Owens, W.H., 1974. Mathematical model studies on factors affecting the magnetic anisotropy of deformed rocks. Tectonophysics 24, 115-131.

Parés, J.M., Dinarès-Turell, J., 1993. Magnetic fabric in two sedimentary rock types from the Southern Pyrenees. J. Geomag. Geoelectr. 45, 193-205.

Parés, J.M., Banda, E., Santanach, P., 1988. Paleomagnetic results from the Southern margin of the Ebro Basin (EN Spain): evidence for a clockwise rotation. Phys. Earth Planet. Sci. 52, 267-282.

Paterson, S.R., Tobisch, O.T., 1993. Pre-lithification structures, deformation mechanisms, and fabric ellipsoids in slumped turbidites from the Pigeon Point Formation, California. Tectonophysics 222, 135-149.

Pearce, G.W., Fueten, F., 1989. An intensive study of magnetic susceptibility anisotropy of amphibolite layers of the Thompson belt, North Manitoba. Tectonophysics 162, 315-329.

Ramsay, J.G., Huber, M.I., 1983. The Techniques of Modern Structural Geology, 1. Strain Analysis. Academic Press, London, $307 \mathrm{pp}$.

Rathore, J.S., 1979. Magnetic susceptibility anisotropy in the Cambrian slate belt of North Wales and correlation with strain. Tectonophysics 53, 83-97.

Rathore, J.S., Courrioux, G., Choukroune, P., 1983. Study of ductile shear zones (Galicia, Spain) using texture goniometry and magnetic fabric methods. Tectonophysics 98, 87-109.

Reguant, S., 1967. El Eoceno marino de Vic. Mem. Inst. Geol. Min. Esp. 67, 330 pp.

Richter, C., van der Pluijm, B.A., 1994. Separation of paramagnetic and ferrimagnetic susceptibilities using low temperature magnetic susceptibilities and comparison with high field methods. Phys. Earth Planet. Inter. 82, 113-123.

Richter, C., van der Pluijm, B., Housen, B., 1993. The quantification of crystallographic preferred orientation using magnetic anisotropy. J. Struct. Geol. 15, 113-116. 
Rochette, P., Jackson, M., Aubourg, C., 1992. Rock magnetism and the interpretation of anisotropy of magnetic susceptibility. Rev. Geophys. 30, 209-226.

Ruf, A.S., Naruk, S.J., Butler, R.F., Calderone, G.J., 1988. Strain and magnetic fabric in the Santa Catalina and Pinaleno mountains metamorphic core complex mylonite zones, Arizona. Tectonics 7, 235-248.

Sagnotti, L., Speranza, F., 1993. Magnetic fabric analysis of the Plio-Pleistocene clayey units of the Sant'Arcangelo basin, southern Italy. Phys. Earth Planet. Inter. 77, 165-176.

Singh, J., Sanderson, D.J., Tarling, D.H., 1975. The magnetic susceptibility anisotropy of deformed rocks from North Cornwall, England. Tectonophysics 27, 141-153.

Taberner, C., Dinarès-Turell, J., Gimènez, J., Docherty, C., 1998. Basin infill architecture and evolution from magnetostratigraphic cross-basin correlations in the southeastern Pyrenean foreland basin. Geol. Soc. Am. Bull. (in press).

Van der Pluijm, B., Marshak, S., 1997. Earth Structure. McGraw-
Hill, New York, 495 pp.

Vergés, J., Martinez, A., 1988. Corte compensado del Pirineo oriental: geometria de las cuencas de antepais y edades de emplazamiento de los mantos de corrimiento. Acta Geol. Hisp. 23 (2), 95-106.

Vetter, J.R., Kodama, K.P., Goldstein, A., 1989. Reorientation of remanent magnetism during tectonic fabric development: an example from the Waynesboro Formation Pennsylvania, USA. Tectonophysics 165, 29-39.

Watson, G.S., 1966. The statistics of orientation data. J. Geol. 74, 786-797.

Williams, G.D., 1985. Thrust tectonics in the south central Pyrenees. J. Struct. Geol. 7, 11-17.

Wood, D.S., Oertel, G., Singh, J., Bennett, H.F., 1976. Strain and anisotropy in rocks. Philos. Trans. R. Soc. London A 283, 27-42.

Woodcock, N.H., 1977. Specification of fabric shapes using an eigenvalue method. Geol. Soc. Am. Bull. 88, 1231-1236. 